\title{
The Impact Of Globalization And Technology On Teaching Business Communication: Reframing And Enlarging World View, Methods, And Content
}

Priscilla Berry, University of Florida-Gainesville, USA

\begin{abstract}
This paper explores the current paradigm shift in the use of technology in the classroom, which is occurring because of technology explosion in society, impact of globalization, necessary reframing, and enlarging of the world view, methods, and content to make business communication classes relevant. The question is whether the classroom should mirror society or whether society will eventually mirror the classroom. If the classroom mirrors society, the responsibility of methods and content becomes an outwardly directed response. In essence, we simply copy what we see happening in technology within the business arena, such as blogs, Facebook, Twitter, or YouTube videos. If society will mirror the classroom, then the content and methods used can determine whether the potential for higher order thinking can be actualized within the society, as a whole, through the pedagogy of business communication. This actualization must come through the structure and use of an ethical core in teaching, with an understanding that technology has the power to both advance innovation and collaboration or mislead and distort, and it is the classroom facilitator's responsibility to foster the realization of the power of technology. The business world is challenging those of us who teach business communication to make use of technology in a more "21st century" manner; not so much in the use of technology, but more in the attitudes that shape its use. In addition to teaching how to use technology for communication, there is a strong push to teach appropriate ethics in its use within a reframed world view.
\end{abstract}

This paper addresses how content and methods must be reframed and how professors must adopt a revised world view that aligns with a culturally diverse audience and a 24/7, communicative, free, and open environment. The power and force of said technology, specifically social-media communication, has the ability to alter the course of lives, communities, corporations, and countries and must be seen as an integral part of the business classroom.

Keywords: Globalization; Technology; Social Media; Business Communication; Business Environment

\section{INTRODUCTION}

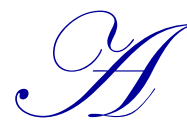

lthough it may sound lofty in terms of our mission as communications teachers, the author believes there are only two forces in the history of civilization that have the power to change anything - one is love and the other is education. We focus on business education as an integral part of these forces for the change necessary to match the requirements of a 21 st century world over which we, as business communication professionals, have influence.

Tom Freidman, who a decade ago wrote The World is Flat, has written a new book called That Used to be $U S$, which brings us up to date on how much the world has changed. He humorously notes that when he wrote The 
World is Flat, the Internet was just starting - and without too much excitement, Facebook did not exist, the Cloud was only in the sky, Twitter was the sound that birds made, and Skype was a typo (Friedman \& Mandelbaum, 2011).

The problem is that the world has changed and education in the United States has not, nor has it assumed the power that it could have in order to be a major player on the world stage. We are still educating our students and teachers about an economy and a world that has passed, neither of which is coming back. For example, a major political debate rages over the outsourcing of jobs and the impact on domestic job opportunities and the U.S. economy at large. On the subject of outsourcing of jobs, no matter how many politicians promise to "bring back our old jobs" to the U.S. and apologize to all the author's friends in powerful political positions, these jobs are not coming back. It is like going down to the ocean, putting your feet in the water, and telling the tide not to come in! It is not happening. In China, they are complaining about the outsourcing of their jobs to Cambodia and Vietnam. Outsourcing is a business model that is succeeding and one that is supported by emerging markets around the world. The jobs that have gone to other countries have raised the education level of the population in these countries and provided markets for the U.S. and other countries. We must acknowledge this shift and make a change in education that explains and supports the new industries and careers of this century. In fact, we (the U.S. or China) do not want these jobs to come back; we want to educate our population for current jobs and those of the future. Initially, the jobs that were exported were low-end service jobs sent to underdeveloped countries; now, however, these countries have developed their own work force and elevated these skills to the next level. Such an action benefits the world economy, and we are inexorably tied to a world economy. Our mission as business communicators, which is by far the most important part of business education, is to teach the use of technology within the classroom and advance our students' knowledge to foster their sense of power as they go into business, communicating through technology.

The first step in this process is for educators to retrofit their own mindset and to enlarge their educational experiences, as the mission of education in the $21^{\text {st }}$ century is to prepare students for this "flat world" where Western culture may or may not be dominant. The statistics quoted for the economy are often manipulated for political purposes; one such example is how the numbers for the United States' decline in manufacturing are skewed. They are indicative of a world that has forever changed. Dr. David Altig, the VP of Research at the Atlanta Federal Reserve Bank, spoke in October 2011 at the Hough Graduate School at University of Florida and explained that we have remained rather steady in manufacturing since the 1950s, and although the number of jobs in the manufacturing sector has declined sharply, the manufacturing output remains consistent. We are now automated in ways that are hard to imagine. He said that those in the Federal Reserve joke that manufacturing will come down to one man and one dog and the dog will be there to make sure the man does not touch anything. This is just one example of an industry that has dramatically changed its work force requirements. It is a different world.

To underscore the importance of what we say and do in today's business classroom, Friedman explains in That Used to Be US that if Hillary Clinton had asked for advice (noting that she did not) when she talked with President-elect Obama, Friedman would have told her to tell the President that she did not want to be Secretary of State. The position of Secretary of State focuses only on administering foreign policy through the State Department and Foreign Services and through meeting with all Heads of State around the world. Rather, Friedman suggests she should want a position more aligned with National Security. "Mr. President", Friedman has her say, "I want to be Secretary of Education." (Friedman \& Mandelbaum, 2011)

In the $21^{\text {st }}$ century, we must change the nature of our discussions about education. As professors in business, we frequently frame the discussion of education as a social issue; what informs the discussion most are issues, such as keeping people out of poverty via education, educating the population for jobs, or supplying business with an appropriate work force. This kind of social discussion is no longer adequate and we must change it - take it to the level that is appropriate for the world our students are inheriting, a world where their education becomes a matter of national security. What we are called to do involves more than teaching proficiency with the American Psychological Association Style Manual (APA), or the rules and mechanics of grammar, or format of a business letter.

The dialogue around education must be about global economics and national security, as Friedman indicates. The stakes are higher now than they have ever been and our survival in the top tier of the world depends on how we meet this challenge. It is not pretentious to maintain that it is in the world's best interest for America, 
and the other evolved nations of the world, to remain as leaders of the pack. How we educate our business students, many of whom are international students, will determine the future of our country and the world.

\section{What Does That Mean To Us In The Classroom And How Can We Retrofit And Rise To The Challenge?}

First, we must be motivated to do this, and the main source of motivation will come from the environment in which we live and work now. It is almost impossible to learn all of what we need to know about the technical aspects of using social media, including Facebook, Twitter, LinkedIn, blogs, iCloud, iChatter, and how to use them in the business classroom, without being in a community that speaks this language. We must dialogue, try, apply, and be open to learning every moment. Beyond technical knowledge, which is a prerequisite for teaching business communication, a larger world view is imperative for teaching business communication (Epper \& Bates, 2001).

Second, we must not be afraid. As a facilitator in the classroom, we must adopt the attitude of total confidence in knowing who we are and why we are here. If someone seems to know something, that as classroom facilitators we do not, this should excite - rather than intimidate - us. Simply, it is only a book we have not read yet! This must all be framed by a belief that what we do in the classroom really matters. We have the opportunity to train and shape beliefs about learning and ethics and future business leaders can be influenced in a positive way by how we teach business communication (Lutz, 2003).

Third, committed to life-long learning, as we are, fortunately or unfortunately, we must be extraordinarily topical. Gone are the days when we could luxuriate over our favorite novel or fiction writer. We cannot just read To Kill a Mockingbird one more time. Sorry! The world is moving fast and we must be armed with the facts and challenge our students to move at the same pace. Business demands it! The influence of globalization is by far the most challenging force in education and, as business communication instructors, we must have an understanding of and opinion about globalization.

\section{ADOPT A WORLD VIEW THAT ADAPTS TO A CULTURALLY DIVERSE AUDIENCE}

What must be the philosophy, mindset, and world view of a business communications instructor in a $21^{\text {st }}$ century college classroom?

The answer begins with a line from Alfred Tennyson's Le Morte D 'Arthur. King Arthur, as he is dying, is questioned by Belvedere, his Knight of the Roundtable, "But now the whole Round Table is dissolved/which was an image of the mighty world;/... and the days darken round me, and the years,/among new men, strange faces, other minds./and slowly answered Arthur from the barge, "The old order changeth, yielding place to the new ..." For many of us, what was the "old order" that has changed completely, and even for young instructors who are teaching just out of graduate school, the world is forever changed by the actions and events of 9/11. The impact of globalization and the explosion of technology for the classroom and learning are felt even as we speak. It is no longer acceptable to present a totally Western culture viewpoint as the way of seeing the world; however, we should not walk in the other direction so completely that we attempt to homogenize world culture. The old idea that we are a melting pot is passé and a more accurate interpretation of world society is that we are a mosaic, all wanting to be part of the picture, but desiring to remain distinct and different.

Business communication instructors teach multiple business disciplines and we are responsible for teaching the most important skill set that students must master for success in the real world, which is now an international world. The idea that a person will go to work for one employer and retire from that position is a myth; there are estimates that employees will move five or more times during their professional lives. They will move not only from one company to another but will move from one country to another. As teachers, we cannot assume one cultural view of communication and we cannot teach from a solely Western perspective. Students who graduate from our prestigious business programs must be prepared to understand cultures other than their own. (Just a note: the study abroad programs are often not long enough in duration to constitute real cultural immersion.)

The demographics in our classroom have also changed. Five years ago, there were only a few foreign students; now, in graduate classes, there are frequently more Chinese, Indian, Latin American, and Arab students 
than there are Western students. Universities in the United States are still the most desired place for earning an education; however, there are a growing number of well-known international universities that are attractive to students, such as the London School of Economics, University of Edinburgh, Tokyo University, and McGill University in Canada, to name a few. The number of international students attending colleges and universities in the United States, according to the Institute of International Education (November 2011), which publishes its Open Doors report annually, increased by 5\% - 723,277 - during the 2010-2011 academic year, with the majority coming from China.

As facilitators in classrooms, it is important that we capitalize on the richness that this new dynamic presents. We cannot assume that all foreign students who come to the U.S. are seeking to develop Western thought. In fact, we can most accurately assume that the majority is not seeking such an enculturation; they desire to learn how to do business within the Western markets, and thus there is a necessity to learn the language and the skills for effective communication. This dynamic also presents the perfect opportunity to discuss values as they relate to communication between cultures. Personal stories around the five areas of gender, age, handicap, ethnicity, and sexual orientation (using APA guidelines for Bias in Language from the $6^{\text {th }}$ edition is helpful) provide a way to create an international knowledge base. The crucible of learning, that can be created in such a classroom with both Western and foreign students, can foster an excellent scenario for students to learn from their peers, most particularly in specially designed team projects that require collaboration. Mastering the language skills for writing and speaking are paramount for foreign students, and gaining an understanding of the culture and thought processes of foreign students is of the utmost benefit for Western students. Again, the team projects that involve problemsolving for corporate communication scenarios are the most convenient way to facilitate this process and it must be elucidated that the goal of these assignments is not simply the product or outcome; the process of sharing and building relationships is the most important part. These team projects can easily require that students communicate in all channels and technologies used by business.

It is imperative that the instructor bring to the table an understanding of the foreign cultures that will be a part of the classroom. Although a majority will agree that the language of business is and will be English, the jury is still out on whether the yen, the dollar, or the euro (... although currently the euro is not looking too strong) will be the world currency. However, although the Chinese, Indians, or Latin Americans will speak English, they will continue to think as Chinese, Indian, or Latin Americans - and so will the Europeans - who are highly nationalistic and have a tremendous diversity of thought. These kind of nuances play out in the classrooms and they must be incorporated into the environment created for new global classrooms in communications. Carefully guided classroom discussion around cultural differences can prove enlightening for all class members. What is relative here is that facilitators are topical enough, with sufficient cultural immersion, to run this type of classroom discussion and that they are comfortable and open enough to freely acknowledge what they do not know.

One thing that is most helpful is to bring in outside speakers who can address any of the topics you want to cover in your classroom - speakers who bring another paradigm from which to view the topic. People from multinational corporations, who are doing business within the international environment, can bring a dynamic to a multi-layered classroom that will enable students to really "hear" the message of the importance of communication skills and consider the international culture of business. Occasionally, the on-campus professors in the language department will accept an invitation to speak to a business communications class on the cultural nuances involved in communication. Another important source - and one that might be overlooked - is the history department. Although the advances in technology today make the past seem archaic (especially to the Millennials), we must be made aware of the major paradigm shifts that were experienced during other historic global transitions, which will provide a valuable context (MacGillivray, 2006). This discussion can be most helpful in raising awareness for the necessity of higher-level skills in writing and speaking; however, beyond those skills, there is much to learn about international culture to be successful in business communication in the $21^{\text {st }}$ century.

\section{REFRAMING CONTENT AND METHODS: ASSESSING THE IMPACT OF GLOBALIZATION ON BUSINESS COMMUNICATION}

What is the content for business communications courses and how is it best framed for the $21^{\text {st }}$ century? What are the best and most effective methods for teaching this content? 
It is imperative that we as professionals accept the challenge of change that an interconnected world and a wired campus present. The newly elected Dean of the Harvard School of Business, Nitan Nohria, the first nonWestern-born business Dean, writes and speaks articulately about the new century: "If the $20^{\text {th }}$ century was the American century for business, the $21^{\text {st }}$ century is decidedly a global century and this (meaning Harvard) must be the place where the world's best thinking about business and management practices takes place." This kind of thinking must be pervasive everywhere we teach (Harvard Business School Homepage, 2012).

Our new globalized world must shape our content. Learning involves seeing ideas and knowledge in a different way than a student's culture may have trained them to see. Hopefully, we are receiving our population at a young enough age to have the potential of receiving open minds. We need to take advantage of this openness; however, it is important to know that what we are trying to do is move students to the point where what they know now becomes stronger than what they have been taught to believe. Helping students to assess their cultural background for business is an essential part of the content in a business communications course; for example, the more casual and relaxed style of doing business in Western culture is in sharp contrast to communication in Europe and in China. How can we have content that is global in application without awareness of the differences in communication styles around the world? In reality, a semester course is not enough time to teach all foreign styles of communication; however, we need specific examples that illustrate the stark differences. One story that is onpoint is the one of Jack Welch's late career failures in international communication. It was with an Italian head of Honeywell - Jack traveled alone to Italy to meet with the Monsieur, which is, in and of itself, a mistake that Western business people make. In other cultures, the do-it-yourself and independent style of the Western culture of traveling without attendants is seen as rather uneducated and unsophisticated. Jack, supposedly, according to the book Control Your Destiny or Someone Else Will: The Jack Welch Era: How Will History Remember Him? by Tichy and Sherman, lost a $\$ 48$ billion deal for GE. The scenario is that meeting for the first time, and after a long plane ride, the Italian head of Honeywell, Jack loosened his tie and extended his hand to speak and said something akin to, "Let's just get down to business and talk." The Monsieur stepped back and said, "Mr. Welch, we will keep our ties tied and our clothes on for this meeting."

The best opportunity we have in our course is to spend time with raising awareness through communication stories, such as the ones outlined in the Lehman and Dufrene Business Communications text (2011). The authors, in just one short section on Diversity Challenges as a Strategic Force Influencing Communication, outline three major stories that highlight what seemed like small queues to a major disaster. One is the McDonald's World Cup soccer championship advertising campaign that put the flags of the 24 participating countries on Happy Meals. The flag of Saudi Arabia contained words from the Koran; the holy words would be smeared in ketchup and thrown in the trash - two million Happy Meals, in fact - as quoted by Lehman and Dufrene (2011).

A second Lehman and Dufrene story highlights international communication mistakes relating to the ninemonth long and frequent traveling business negotiations from a NAFTA deal between the U.S. and Mexico which was finally sealed and the U.S. negotiators flew home for the last time with the deal made. The U.S. representatives of NAFTA faxed the contract to the Mexican CEO for signing; however, the CEO refused to sign because of the casual attitude implied via a simple fax. Again, this scenario highlights the failed understanding of the cultural implications for all business communication.

We have an obligation to enable students to realize the real impact that globalization has on business communication and to incorporate these realities into the content of our course. In short, students must do their homework and know that no shortcuts are allowed. We cannot do it for them; our job is to make them aware and to realize the impact of globalization in context to what they write and say.

It would be impractical as business communication instructors to ignore the basics - we cannot. However, how we present this information and how much time we spend talking about the basics is within our control. The idea that we should remediate for writing in the college classroom has to be taken off the board and the only people who should have the power to do that are the classroom teachers. We have, for too long, pandered to the system and spent untold hours with track changes. When an undergraduate student somehow gets through the system and presents without the basic skill set to write using Standard English, we need to sound an alarm. The system that recruits students must be held accountable for the student and provide a realistic tutoring lab for the student to gain 
the kind of practice and reinforcement that is necessary to develop strong writing skills. Instructors are trying to do it all in a traditional 15- or 7-week module semester. We are not helping the reputation of the school we serve, nor are we supporting our most important product - the student. Businesses are now responding to the schools, indicating that they will not hire their graduates if they cannot read, speak, and write proficiently, which also means that students must believe it as well.

Another challenge that must be faced is the security around the testing of foreign students (note: students are foreign when they come here and we are international when we go there) who are flooding the ranks of U.S. schools all over the country. At one time, these students were guided to only large and big-named schools; this trend has changed, and they now seek out smaller and lesser-known schools. Additionally, we know that there is so much pressure on foreign families to get their children into these schools that they pay large sums of money to have intermediaries package their children and, even in some cases, pay to have someone take the test for the student. As teachers, we cannot police the cheating factor; however, it is an issue that schools must address. What we can do is speak directly to our administration about the essential requirement that students must come to us already equipped with the ability to read English with comprehension, to write standard English, and to speak intelligible English. Once international students arrive on campus, they are assigned by administration or they personally recruit a Western-born tutor to assist them. This scheme has merits; however, the Western students are often tempted to intervene at many levels for the international students, often pleading with instructors or putting pressure on them to grade international student differently. There is a great deal of professional dialogue that must take place around this challenge. The diversity of students in our business programs is such a welcomed force in our universities and colleges and is such a necessity if we are to continue to have a business impact in the world. We must be global in our thinking and local in our demand for certain standards to be met.

Another hurdle for the business communications class is that this course is not like a standard English writing course. It would not be meaningful to speak in detail of this challenge to instructors who teach English courses; however, the shift in content is a dramatic one from an English to a business class. We are teaching students to be competitive and how to position what they write and what they say to be specific and targeted. We make them use fewer words and in a different language. Students come into a business class without business words and the only way to expose them quickly to the vocabulary of business is to make them read. Perhaps we use The New York Times, The Wall Street Journal, or Financial Times; nevertheless, specific assignments are made and checked. The Wall Street Journal provides educational assistance with lesson plans and rich ancillary teaching material. For some assignments, we play word games for 10 minutes during class, which includes finding and talking about students' new business vocabulary words of the day. Students are often assigned a business reading and are required to stand in front of the class and present the contents of the article with their own business commentary.

Globalization is a gradual process and then, all of a sudden, it seems we are there. The world is changing at an exponential rate and the difference this makes is that the process of globalization has accelerated at a rate that is almost incomprehensible. Not only is it often incomprehensible, but it also happens in such a way that we are not at all impressed; in fact, in Western culture, technology explosion is almost assumed to occur. In today's knowledge economy, for better or worse, the more globalized a country is, the less the poverty, and the more globalized the business communications curriculum is, the richer the outcome for the students (Economist Intelligence, 2008).

The idea that we would focus on a strictly "memorize and repeat" methodology in the classroom is absurd and one that has been replaced with access to all available sources of information. For the final exam, the instructions are that teams can use any source of information they can find, and all sources are open to them. It is no longer relevant to require rote memorization when the information is so accessible and available instantly on any hand-held device. Students must learn to apply critical-thinking skills, be immersed in the world around them, and be topical in a detailed fashion, coupled with the skill of conducting research and applying that to their writing and speaking. 


\section{EXPLORING THE POWER AND FORCE OF TECHNOLOGY AND SOCIAL MEDIA COMMUNICATION TO ALTER THE COURSE OF LIVES, COMMUNITIES, CORPORATIONS, AND COUNTRIES}

Things are now possible that we could not have imagined in education just a few years ago and it is an exciting time to be alive and to be teaching. Successfully adapting the business communications classroom to employ the best of social media is essential. A business that does not use social media is not marketing itself, which is essential for businesses to grow in today's economy; a classroom that does not employ social media is missing the perfect setting for getting students to do what we really need for them to do - practice writing and speaking. For example, two blogs were started at the beginning of the semester - one was a personal blog related to skill development, goals, and achievements, and the other was a professional blog related to the concepts, facts, and professional information from the course that could prove valuable to the students and to the instructor. On these blogs, students could individually answer a questions like, "So what did you learn in this class?" The blogs provided an opportunity for students to introspect in terms of identifying the skills that must be acquired to be successful in their career of choice. Requiring students to post on a blog can challenge the blogger to a notoriety that encourages a better and stronger level of writing, with the writer paying more attention to the nuances of style and rules of grammar.

Some students are social media savvy and this should definitely be successfully coopted in the business curriculum and in the business communication class. All professionals are encouraged to use LinkedIn; students who do not have this page when they first come to the class must develop the ability to use LinkedIn's networking powers and to learn about career opportunities before they leave the class. To create or update the students' use and visibility on social media during class time, through peer review, is an excellent assignment that provides a great deal of feedback and frees up the instructor's time.

Individual assignments that require students to use social media to market their most important product themselves - meet important requirements for business communication classes. Having students create a web page using one of the many available free sites enables the instructor to discuss subjects, such as professionalism in communication. A student's web page is a marketing tool for them. The web page should have a pdf downloadable copy of the résumé and be a site to post writing samples from their business communication and other classes. The free sites offer simple tutorials for the students and developing a web page is an easy assignment for instructors to grade. The web page can provide a productive learning experience within the course. The web page assignment encourages students to write well, increases their awareness of professionalism, teaches them how to market what they write, and emphasizes how important what they write is to their success in a career.

From the good to the bad and the ugly, instructors are requested to tell as many stories as they know about how jobs are lost, or never offered, how careers are ruined and the course of lives forever changed because of the misuse of social media. Corporations search all social media sites, including the ones people believe are hidden except to certain viewers, to gather information about job seekers and current employees. This may or may not be legal, but that is not the debate here. The point is that for students with career goals in business, there can be no pictures of red Solo cups in hand. Amazingly, this is a hard concept to convey. There is an urgent need to convey the message that all information on the web is public and must be controlled. Social media is a powerful tool that is used to market, and students must understand that everything they put into the public domain has the power to create or destroy their business opportunities. Teaching students the power of professional writing and speaking and marketing via social media is the most important thing we can teach! It will be the medium that they will use the most going forward in business.

One of the fascinating things about the use of social media in the classroom is that you can assign students to identify communities of business communication students from other geographical areas and other countries. They can find other subjects' syllabi posted online by other instructors and make projects where they compare the institutions and respective course requirements. As a part of this project, a student recently researched the course requirements of a similarly named course in a university in China and posted a link to a YouTube video of the instructor interacting with the students. It was not a favorable picture; the student posted it on Facebook and an incredibly rich dialogue ensued which is a teacher's dream in terms of insight for students. 
The impact of technology and globalization within our hometown communities has changed the way we live and, in some cases, has shaped who we are. Farming towns, fishing villages, and manufacturing cities are forever changed, and entire communities have been abandoned and cities have declared bankruptcy. The necessity to adapt becomes even more poignant and the need for clear, relevant, and timely communication has become an even more dramatic requirement. Why did no one listen to the prognostications and the voices that spoke loudly about the coming of the big mechanized farms, automated car manufacturing process, and overfishing and ensuing government regulation of the waters? How evident was the Red Box and who could not see it coming? All effects of technology have changed our lives, but often we are blind to what is right in front of us.

The shift to an educated and professional use of social media will make a difference in going forward through our capacity and willingness to be educated and to listen. Business communication students must be aware of this process and must learn to search, use, and become a part of the social media revolution in thought, word, and speech! A significant reference about social media and its impact is Erik Qualman's Socialnomics (2011). Qualman writes that the shift to social media is the greatest change since the Industrial Revolution. Outbound marketing and most forms of one-way communication, such as direct mail, are dead as venues; communicating in the new inbound channel requires a specific kind of business writing for a different target audience. The audience no longer looks for the information they need; it comes to them via Really Simple Syndication (RSS) feeds they select. As teachers in business communication, it would be a really good idea to have your students, while you have influence over them, sign-up for some RSS feeds that will channel and provide them with reading and vocabulary experiences. If they are not strong readers, they have a slim chance of becoming strong writers. The social media provides the opportunity to create reading and writing assignments via a new channel. These are some of the undocumented and notable social media stats presented in the latest videos of Qualman:

- $\quad 96 \%$ of Millennials have joined a social network.

- $\quad$ Social media has overtaken porn as the No. 1 activity on the web.

- 1 out of 8 couples married in the U.S. met via social media.

- $\quad$ The fastest growing segment on Facebook is females 55 to 65 years old.

- It took the radio 38 years, the TV 13 years, the Internet 4 years, and the iPod 3 years to reach 50 million users, while Facebook reportedly added 200 million users in less than one year.

The Socialnomics video's intent seems to convince businesses to invest in their social media strategies: " $25 \%$ of search results for the world's top 20 largest brands are links to user-generated content, $34 \%$ of bloggers post opinions about products and brands", and the YouTube clip warns, asking, "Do you like what they are saying about your brand?" (Qualman, 2011).

Documented or not, the point is made in a powerful way and it is certainly clear to all teachers of communication that communicating via social media is not just a fad or simply for fun, but now serious business venues.

Students will walk into corporate career positions expected to know how to collaborate in team tasks using, say, Google docs, and to understand and coordinate data using iCloud. Corporations are using social media to communicate internally and externally and students must have proficiency in this medium to be successful in the corporate arena; it is a given in today's market environment. Corporations are painfully aware that not creating and feeding social media risks the loss of branding, which is the most powerful force in the corporate arsenal. Using these social media tools in the classroom can enhance writing assignments and provide a fresh way to engage students in writing. The research shows that students expect to make heavy use of technology in the classroom and the credibility of the course is increased by using technology beyond the worn-out PowerPoint (Lavin \& Others, 2011).

It is almost old news to talk about the Arab Spring of 2011 that brought down rulers of countries, deemed despotic by citizens via communication that spread not only the news of the rebellions but also provided a connectivity that was empowering. It is for sure a sea of change! No one knows how it will unfold, remembering that it is one thing to have a rebellion and yet another to have a strong and representative government in place and ready to become full grown, akin to Athena's springing full grown from the head of Zeus. We are now connected in 
ways deemed impossible just a mere five years ago and this connectivity requires a new and bold way of communication, not only in terms of clear use of standard English, but also with knowledge of and sensitivity to cross-cultural communication and to parts of the world that are fragile in many ways. When Edward Bulwer-Lytton wrote in 1839, "The pen is mightier than the sword", I am sure the power of social media would have supplanted the pen, if he had known.

The January edition (2012) of Fortune titled "The Future Issue" quotes Steve Jobs who supposedly said, "The only way to predict the future is to invent it." (Eason, 2012, p.45) As business communication teachers, we may not be able to predict or invent the future, but we can teach in the moment and avoid the trap of teaching using yesterday's techniques. The projections of future technologies in this article, like supercomputers that will fit in the palm of your hand, are beyond exciting. The downsides are equally as mind boggling and they all involve communication - cyber war, increased political instability, rogue terrorists and a world shortage of resources. The dark side is always about the takeover of innovation and often innovation in technology, by lower order thinking. In the business communications classroom, we can do something about curbing this tide.

It would be a glaring weakness if the conclusion to this thesis did not indicate that there are many voices that decry the spread of globalization and lament the power of the corporation so to influence the educational programs in business education. The commodification of education (making it into a commodity) is a reality and it may indeed have turned students and teachers into not just participants, but consumers as well (Smith, 2002). It is easily recognized that the pressure to master and use technology, as a way to innovate and stay competitive, is a reality and one graphically realized in the business communication class. Please note that in response to the commodification of education and its institutions, the author's personal dream is to teach a business course to graduate students entitled All the Art, Music, Literature and History You Need to Know to Succeed in Business, thereby taking business communication as far from a commodity as possible and moving it into an art form where we are not consumers, but artists who create and innovate and are prepared to lead in the $21^{\text {st }}$ century.

\section{CONCLUSION}

Businesses will not be local anymore and the realities of globalization demand that we prepare our students, as an integral part of the classroom experience, with technology that changes the methods and content of communication to a $21^{\text {st }}$ century model. A model emerges that will educate, for a knowledgeable economy, one that embraces a highly ethical model in the use of technology and that challenges our world view to remain fluid and shift away from an ethnocentric model to reflect the new economy, which may be beyond the knowledge economy, as we speak, and may have moved to a communications economy. As teachers of business communication, we are required to be both in the world and of the world!

\section{AUTHOR INFORMATION}

Dr. Berry is currently an Adjunct Lecturer in the Hough Graduate School at the Warrington College of Business at UF, and has a private consulting firm: Berry \& Associates, a firm that specializing in programs to assist large corporations to solve internal and external communication challenges - providing workshops and seminars for professional growth and development - leadership and management training. She is a regular columnist for the Jacksonville Business Journal answering questions on careers and professional development. Dr. Berry is passionate about education reform. Her upcoming book, Saving Darwin's Soul, a Journey to Corporate Wellness, is a plea for corporations to take the leadership role and bring sanity back to society. E-mail: priscillaberry@berryleadership.com

\section{REFERENCES}

1. Eason, N. (2012, January 16). Fortune's guide to the future. Fortune: The future issue. 165 (1), pp. 44-46.

2. Economist Intelligence Unit, sponsored by the New Media Consortium. (2008). The future of higher education: How technology will shape learning. The Economist, a white paper. pp. 1-27.

3. Epper, R. and Bates, A. (2001). Teaching faculty how to use technology. American Council on Education. Oryx Press. 
4. $\quad$ Friedman, T.L. \& Mandelbaum, M. (2011). That used to be US: What went wrong with America ... and how it can come back. Little, Brown.

5. Harvard Business School homepage. (2012) retrieved from: http://www.hbs.edu/dean/

6. Institute of International Education. (November 2011). Open door report. retrieved from: http://www.iie.org/en/Research-and-Publications/Open-Doors

7. Lavin, A.M. \& Korte, L., Davies, T. (2011, April). The impact of classroom technology on student behavior. Journal of Technology Research. 2, pp. 65-77.

8. $\quad$ Lehman, C. \& Dufrene, D. (2011). Business Communication. $16^{\text {th }}$ edition. South-Western Cengage Learning.

9. Lutz, J., Briggs, A., \& Cain, K. (2003). An examination of the value of the generation effect for learning new material. Journal of General Psychology, 130 (2), 171-188.

10. MacGillivray, A. (18, April, 2006). Wonderful shrinking world, retrieved from: http://www.opendemocracy.net/globalization-trade_economy_justice/shrinking 3461.jsp

11. Qualman, E. (2011). Socialnomics: how social media transforms the way we live and do business. John Wiley \& Sons.

12. Smith, M. K. (2002) 'Globalization and the incorporation of education' the encyclopedia of informal education,www.infed.org/biblio/globalization.htm.

13. Tichy, N. \& Sherman,S. (2001). Control your destiny or someone else will: The Jack Welch era: how will history remember him. Harper Collins. 